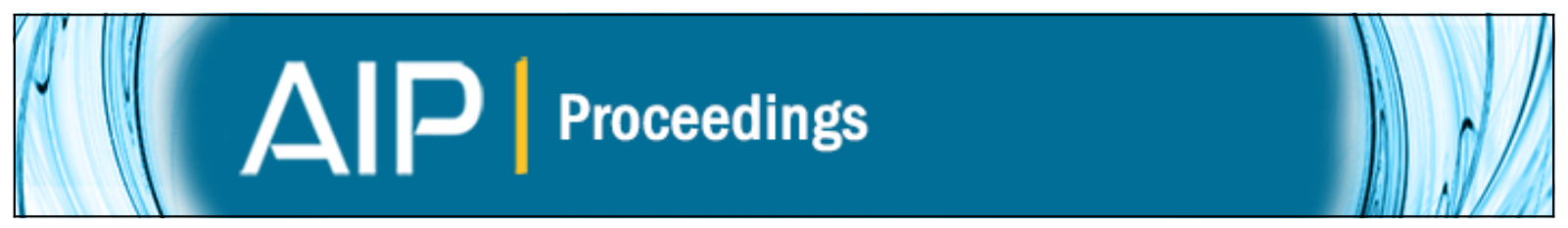

\title{
High renewable content sandwich structures based on flax-basalt hybrids and biobased epoxy polymers
}

S. Colomina, T. Boronat, O. Fenollar, L. Sánchez-Nacher, and R. Balart

Citation: AIP Conference Proceedings 1593, 467 (2014); doi: 10.1063/1.4873823

View online: http://dx.doi.org/10.1063/1.4873823

View Table of Contents: http://scitation.aip.org/content/aip/proceeding/aipcp/1593?ver=pdfcov

Published by the AIP Publishing

\section{Articles you may be interested in}

A high-performance dielectric elastomer consisting of bio-based polyester elastomer and titanium dioxide powder J. Appl. Phys. 114, 154104 (2013); 10.1063/1.4824805

Vertical hybrid microcavity based on a polymer layer sandwiched between porous silicon photonic crystals Appl. Phys. Lett. 95, 163301 (2009); 10.1063/1.3245319

Towards a structural characterization of an epoxy based polymer using small-angle x-ray scattering J. Appl. Phys. 101, 043509 (2007); 10.1063/1.2511890

Calibration of an analytical thermal model for an epoxy-based composite sandwich design AIP Conf. Proc. 552, 304 (2001); 10.1063/1.1357939

Ionic transport in polymer electrolytes based on renewing environments J. Chem. Phys. 100, 3979 (1994); 10.1063/1.466331 


\title{
High Renewable Content Sandwich Structures Based on Flax- Basalt Hybrids and Biobased Epoxy Polymers
}

\author{
S. Colomina, T. Boronat, O. Fenollar, L. Sánchez-Nacher, R. Balart* \\ Instituto de Tecnología de Materiales (ITM), Universitat Politècnica de València (UPV), Campus d'Alcoi, Alacant, \\ Spain-sancopei@epsa.upv.es; tboronat@dimm.upv.es; ocfegi@upv.es; lsanchez@mcm.upv.es; rbalart@mcm.upv.es

\begin{abstract}
In the last years, a growing interest in the development of high environmental efficiency materials has been detected and this situation is more accentuated in the field of polymers and polymer composites. In this work, green composite sandwich structures with high renewable content have been developed with core cork materials. The base resin for composites was a biobased epoxy resin derived from epoxidized vegetable oils. Hybrid basalt-flax fabrics have been used as reinforcements for composites and the influence of the stacking sequence has been evaluated in order to optimize the appropriate laminate structure for the sandwich bases. Core cork materials with different thickness have been used to evaluate performance of sandwich structures thus leading to high renewable content composite sandwich structures. Results show that position of basalt fabrics plays a key role in flexural fracture of sandwich structures due to differences in stiffness between flax and basalt fibers.
\end{abstract}

Keywords: Composite, Epoxidized Vegetable Oil, Basalt, Flax, Cork

\section{INTRODUCTION}

In recent years, a great interest has been focused in the use of vegetable oils as base materials for different thermosetting resins; it is possible to convert conventional vegetable oils (with unsaturated fatty acids such as oleic, linoleic and linolenic acids) to epoxy resins by an epoxidation process. These plantderived epoxy resins can compete with petroleumbased resins as matrices for thermosetting composites. These resins offer an environmentally friendly alternative to petroleum-based resins. However, due to the relatively high cost compared to petroleum-based resins, their use is still restricted to applications with a relatively low consumption volume. One of the sectors with more consumption of epoxy resins is composite manufacturing. Moreover, the use of reinforcing fibers (glass, carbon or natural fibers such as flax, jute, hemp, etc.) and/or light core structures for sandwich composites could represent an attracting alternative for conventional composite structures [1].

The aim of this work is to develop and evaluate sandwich structures with high renewable content materials. For this reason, a cork material was used as core of the sandwich structures, and hybrid basalt-flax fabrics were used as reinforcements for the composites.

\section{EXPERIMENTAL}

The partially biobased epoxy resin was supplied by Sicomin Composites, commercial grade Greenpoxy 55. This resin contents, at least, a 55\% of sourced carbon derived from vegetables. The resin:hardener weight ratio used was 100:40 as recommended by the supplier.

The resin was crosslinked at room temperature during 24 hours to minimize residual stresses as a consequence of curing. Nevertheless it is important to point that tempering could influence final mechanical properties and this topic could be of interest for further investigations. To reinforce the sandwich structures, flax $\left(230 \mathrm{~g} / \mathrm{m}^{2}\right)$ and basalt $\left(630 \mathrm{~g} / \mathrm{m}^{2}\right)$ plain wave fabrics were used. These fabrics were selected as they allow easy vacuum infusion process. Flax contributes to high renewable content composite structures and basalt contributes to stiffness and overall mechanical performance.

The sandwich panels were manufactured with Corecork NL10 with homogeneous density of 140 $\mathrm{kg} / \mathrm{m}^{3}$ supplied by Amorim Group. This cork grade is widely used in lightweight composite structures. Laminate manufacturing was carried out by conventional hand layup and subsequent vacuum bagging. Sandwich structures were manufactured with different stacking sequence with regard to flax and basalt fabrics as indicated in Tab. 1.

TABLE 1 - Different composition of the sandwich structures (F-flax fabric; B- basalt fabric; C- core cork).

\begin{tabular}{c}
\hline COMPOSITIONS \\
\hline F-F-F-F-C-F-F-F-F \\
B-F-F-B-C-B-F-F-B \\
F-B-B-F-C-F-B-B-F \\
F-F-B-B-C-B-B-F-F \\
B-B-F-F-C-B-B-F-F \\
B-B-B-B-C-B-B-B-B \\
\hline
\end{tabular}


With regard to the core material, different cork thickness (4 and $10 \mathrm{~mm}$ ) was used for sandwiches.

Flexural tests were used to evaluate the influence of the stacking sequence on final mechanical properties. The most important properties that could be determined by the flexural test were: core shear stress and facing bending stress. The core shear stress was calculated using the following expression:

$$
\tau=\frac{P}{(d+c) \cdot b}
$$

FIGURE 1 - Core shear stress formula.

Where $\tau(\mathrm{MPa})$ is the core shear stress, $\mathrm{P}(\mathrm{N})$ is the load (single-point midspan load), $d(\mathrm{~mm})$ is the sandwich thickness, $c(\mathrm{~mm})$ is the core thickness and $b$ $(\mathrm{mm})$ is the sandwich width.

On the other hand the facing bending stress was calculated using the following expression:

$$
\sigma=\frac{P}{2 \cdot t \cdot(d+c) \cdot b}
$$

FIGURE 2 - Facing bending stress formula.

Where $\sigma$ is the stress in the interface (MPa), $t$ is the thickness of the laminate $(\mathrm{mm}), d$ is the thickness of the sandwich (mm), $c$ is the thickness of the core cork (mm).

The flexural (three point bending) tests were carried out with a universal machine ELIB 30 (SAE Ibertest, Madrid, Spain). Tests were carried out at a strain rate of $5 \mathrm{~mm} / \mathrm{min}$ following the guidelines of ASTM C39300 titled "Standard Test Method for Flexural Properties of Sandwich Constructions".

Flexural test type was three-point bending, where the sample rests on two supports and it is loaded in a central location. The distance between the supports is adapted to the size of the sample; in this case we used a constant distance of $100 \mathrm{~mm}$. At least five different specimens were tested and average values were calculated. Some samples showed core crush under the loading point. These samples were discarded for calculation but images were taken to compare with other layer stacking sequences.

\section{RESULTS AND DISCUSSION}

The results obtained with the flexural test can be observed in Tab. 2.

It is possible to observe, as the core shear stress values are higher than the values supported by the interface of the materials. In addition, we can conclude that the addition of basalt fabrics contributes to increase stiffness so that, optimum results are obtained with a balance between flax (environmental friendly fabric) and basalt (high stiffness fabric).

TABLE 2 - Results of flexural tests of flax-basalt sandwich structures with different configurations.

\begin{tabular}{ccc}
\hline CONFIGURATION & $\begin{array}{c}\text { core stress } \\
(\mathbf{M P a})\end{array}$ & $\begin{array}{c}\text { interface } \\
\text { stress (Pa) }\end{array}$ \\
\hline F-F-F-F-C4-F-F-F-F & 4.71 & 345.41 \\
F-F-F-F-C10-F-F-F-F & 3.25 & 202.14 \\
B-F-F-B-C4-B-F-F-B & 8.01 & 581.18 \\
B-F-F-B-C10-B-F-F-B & 5.36 & 366.05 \\
F-B-B-F-C4-F-B-B-F & 7.95 & 508.03 \\
F-B-B-F-C10-F-B-B-F & 2.79 & 184.08 \\
F-F-B-B-C4-B-B-F-F & 5.91 & 428.93 \\
F-F-B-B-C10-B-B-F-F & 3.64 & 233.37 \\
B-B-F-F-C4-F-F-B-B & 8.23 & 556.62 \\
B-B-F-F-C10-F-F-B-B & 5.26 & 335.81 \\
B-B-B-B-C4-B-B-B-B & 12.07 & 797.73 \\
B-B-B-B-C10-B-B-B-B & 4.84 & 334.6 \\
\hline
\end{tabular}

As we can see in Fig. 3 the core stress values obtained with the samples made with a core cork of 4 $\mathrm{mm}$ of thickness, are higher than the samples made with a core cork of $10 \mathrm{~mm}$.

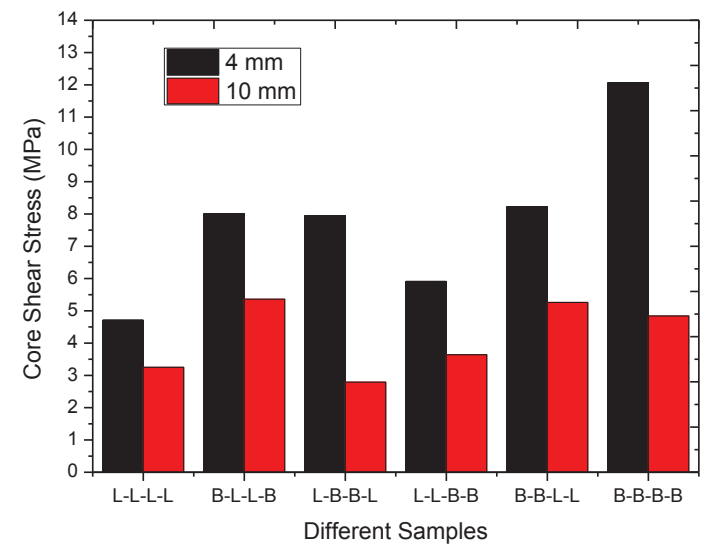

FIGURE 3 - Comparative of the core shear stress obtained with samples with core cork of 4 and $10 \mathrm{~mm}$.

We can highlight that panels with a cork of $4 \mathrm{~mm}$ receive more energy in the center of the panel than panels made with $10 \mathrm{~mm}$. This is due to the main function of the cork core which is the absorption and distribution of the stresses [2].

On the other hand, the stacking sequence of the different composite panels is a key factor on final properties. The sandwich structures made only with basalt fabrics show the highest results with regard to core shear stress. This is evident as basalt fiber has similar properties to glass fiber with an elastic modulus of about $90 \mathrm{GPa}$. On the other hand, the sandwich structures manufactured with flax fabrics show lower 
mechanical properties. This is evident as flax fibers are less stiff than basalt fibers (typical Young's modulus of technical flax is close to $50 \mathrm{MPa}$ while conventional flax fibers as used in this study are characterized by lower values). Nevertheless it is important to remark that the goal of this research work is to find a balance between mechanical performance and environmental friendly nature so that, combination of basalt fabrics with flax fabrics can positively contribute to this objective.

Fig. 4 shows a comparative bar plot with regard to the shear stress for composite panels with different flax-basalt stacking sequence and different core-cork (4 and $10 \mathrm{~mm}$ thickness). We clearly see that panels with eight basalt fabrics (BBBBCBBBB) show the highest shear stress value and this is higher for composites with $4 \mathrm{~mm}$ thickness core cork. [3]

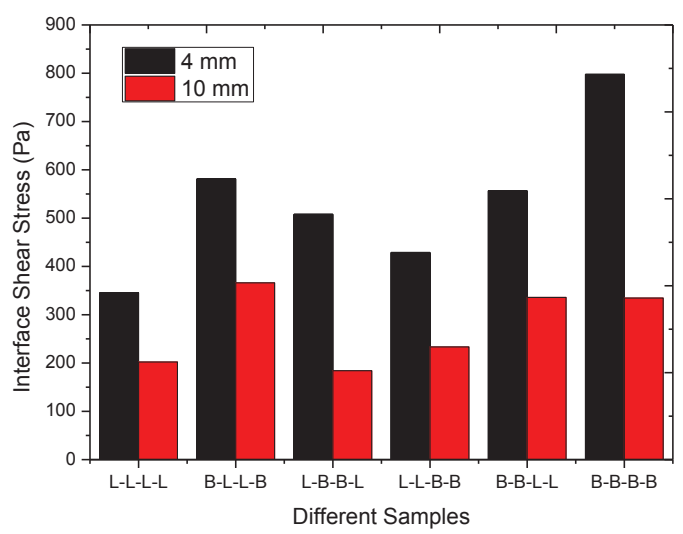

FIGURE 4 - Comparative graph of the interface shear stress obtained with samples with core cork of 4 and $10 \mathrm{~mm}$

Finally, the responses are compared in tests with each of the compositions (Fig. 5). It is important to remark that the stacking sequence plays a key role in fracture of sandwich panels. As basalt fabrics are characterized by high stiffness, if basalt fabrics are in contact with the core cork material, the basalt fabrics are easily debonded since they are too rigid in comparison to the cork core which is a high flexibility material. Nevertheless, when the basalt fibers are at the outside part of the composite panels, the flax fabrics are also flexible and no debonding occurs as observed in Fig. 5. [4]

\section{CONCLUSION}

The overall results show that it is possible to obtain highly environmentally friendly sandwich structures by using a combination of flax and basalt fabrics. Flax contributes to high renewable content composites and basalt is responsible for mechanical performance. On the other hand, the use of cork as core material for sandwich manufacturing is an interesting solution to obtain high lightness composite materials.

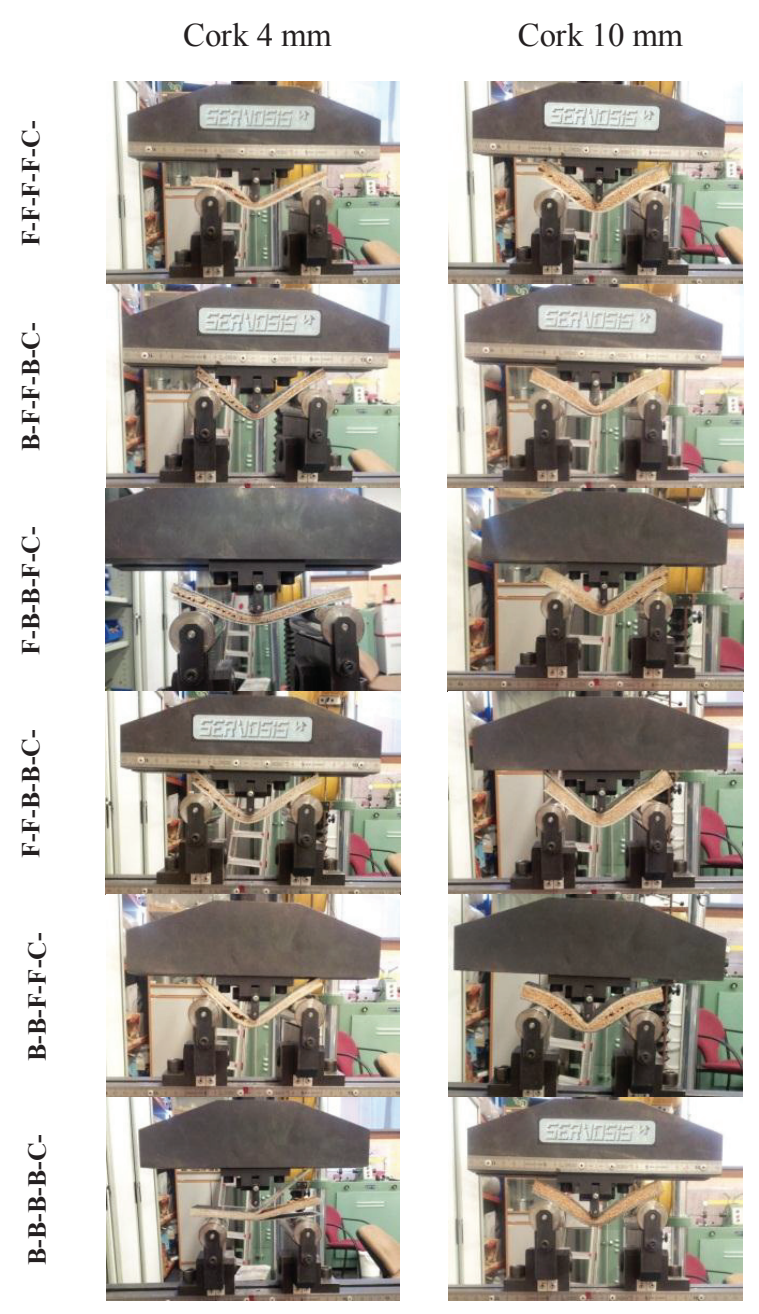

Figure 5 - Images of flexural test of sandwich panels with different cork thickness and flax-basalt stacking sequence.

The stacking sequence of flax and basalt fabrics is a key factor to be considered. The experimental results have revealed that it is preferable to place the basalt fabrics at the outer layers since basalt is a high stiffness fiber and it is not flexible; so that, when subjected to bending stresses the basalt fabrics are easily debonded if they are located at the inner layers. As flax fabrics are more flexible it is necessary to place them at the inner layers in contact with the core cork material to support the bending stress.

As a global conclusion we must remark that the use of a combination of flax fabrics (inner layers) together with basalt fabrics (outer layers) is a technical solution to obtain high renewable content composite materials for uses in engineering.

\section{REFERENCES}

1. D. Bertomeu; D. Garcia-Sanoguera; O. Fenollar; T. Boronat; R. Balart. Polym. Composite. 2012, 33, 68. 
2. F. Roussiere; C. Baley, G. Godard, D. Burr; Appl. Compos. Mater. 2012, 19, 171.

3. A. S. Virk, W. Hall, J. Summerscales; Mater. Sci. Technol. 2012, 28, 864.
4. K. Sungmin, E. Mech, Libraries Massachusetts Institute of Technology, 2011, 115. 